\title{
Effects of an Auditory Lateralization Training in Children Suspected to Central Auditory Processing Disorder
}

\author{
Yones Lotfi ${ }^{1}$, Abdollah Moosavi ${ }^{2}$, Farzaneh Zamiri Abdollahi ${ }^{3}$, \\ Enayatollah Bakhshi ${ }^{4}$, and Hamed Sadjedi ${ }^{5}$ \\ ${ }^{1}$ Audiology Department, University of Social Welfare and Rehabilitation Sciences, Tehran, \\ ${ }^{2}$ Iran University of Medical Sciences, Tehran, \\ ${ }^{3}$ Audiology Department, University of Social Welfare and Rehabilitation Sciences, Tehran, \\ ${ }^{4}$ Biostatistics Department, University of Social Welfare and Rehabilitation Sciences, Tehran, \\ ${ }^{5}$ Engineering Faculty, Shahed University, Tehran, Iran
}

\author{
Received May 30, 2016 \\ Revised July 14, 2016 \\ Accepted August 3,2016
}

\section{Address for correspondence Farzaneh Zamiri Abdollahi, PhD Audiology Department, University of Social Welfare and Rehabilitation Sciences, Koodakyar Alley, Daneshjoo Blv., Evin, Tehran, Iran \\ Tel +9821222180008 \\ Fax +982122180121 \\ E-mail audiology_zamiri@yahoo. com}

Background and Objectives: Central auditory processing disorder [(C)APD] refers to a deficit in auditory stimuli processing in nervous system that is not due to higher-order language or cognitive factors. One of the problems in children with (C)APD is spatial difficulties which have been overlooked despite their significance. Localization is an auditory ability to detect sound sources in space and can help to differentiate between the desired speech from other simultaneous sound sources. Aim of this research was investigating effects of an auditory lateralization training on speech perception in presence of noise/competing signals in children suspected to (C)APD. Subjects and Methods: In this analytical interventional study, 60 children suspected to (C)APD were selected based on multiple auditory processing assessment subtests. They were randomly divided into two groups: control (mean age 9.07) and training groups (mean age 9.00). Training program consisted of detection and pointing to sound sources delivered with interaural time differences under headphones for 12 formal sessions (6 weeks). Spatial word recognition score (WRS) and monaural selective auditory attention test (mSAAT) were used to follow the auditory lateralization training effects. Results: This study showed that in the training group, mSAAT score and spatial WRS in noise ( $p$ value $\leq 0.001)$ improved significantly after the auditory lateralization training. Conclusions: We used auditory lateralization training for 6 weeks and showed that auditory lateralization can improve speech understanding in noise significantly. The generalization of this results needs further researches.

J Audiol Otol 2016;20(2):102-108

KEY WORDS: Central auditory processing · Speech in noise · Sound lateralization · Training.

\section{Introduction}

Sound localization is one of the most important functions of auditory system in humans and other animals and is mainly achievable by using binaural cues including interaural time difference (ITD)/phase difference and interaural level difference (ILD)/intensity difference. Accurate sound localization in animals is crucial for survival (escaping from a

This is an Open Access article distributed under the terms of the Creative Commons Attribution Non-Commercial License (http://creativecommons.org/licenses/by-nc/3.0/) which permits unrestricted non-commercial use, distribution, and reproduction in any medium, provided the original work is properly cited. predator, hunting a prey and finding a mate) [1,2]. In addition, sound localization is an auditory ability to detect sound sources in the space (auditory scene analysis). This type of segregating and grouping of sound sources can help to differentiate between the desired stream of speech and other simultaneous sound sources that can be regarded as noise $[3,4]$. Therefore it is one of the important auditory functions for understanding and following target speech in everyday situations [5]. It is known that speech perception in noise or in presence of competing signals is better when target speech and competing signal arrive from different spatial directions [6] and auditory localization in humans forms a base for higher order 
auditory functions (cocktail party effect) [4,7].

Central auditory processing disorder [(C)APD] is a deficit in auditory neural processing that is not caused by higher-order language, cognitive or related factors [8]. Earlier identification of (C)APD can lead to a more timely diagnosis, which in turn may assist in a better understanding of the child's poor academic performance. This may also increase the opportunity for appropriate and earlier intervention, thus minimizing educational and other associated deficits and improving everyday listening functions [9]. One of the problems in children with (C)APD is localization/lateralization difficulties or spatial processing disorders (SPDs) [10-12]. SPDs have been overlooked in children with (C)APD despite their significance. Dillon and Cameron maintained that a substantial proportion of children with (C)APD suffer from SPD and this may interfere with sound source segregation and understanding of speech in presence of competing sound sources $[13,14]$. It can be especially problematic in classroom [15] where higher signal to noise ratio (SNR) is needed [14] and may lead to academic failure [16].

It is supposed that auditory localization/lateralization training may change children' ability to use spatial clues for segregating target speech from competing signals/noise and improve their speech perception in everyday listening situations. So aim of the present research was investigating effects of an auditory lateralization training on speech perception in presence of competing signals/noise in children suspected to (C) APD. As it is difficult to diagnose children with pure (C)APD, term "suspected to (C)APD" seems more appropriate [17].

\section{Subjects and Methods}

In this analytical interventional study, 60 children suspected to (C)APD (40 boys and 20 girls) were selected based on inclusion criteria. All inclusion criteria were same for training and control group and children who met inclusion criteria were randomly divided into two groups: 30 children in the control group (mean age $9.07 \pm 1.25$ years; 10 females and 20 males) and 30 children in the training group (mean age $9.00 \pm 1.28 ; 10$ females and 20 males). Both groups were matched in terms of sex and age. As there is not a gold standard test for (C)APD diagnosis, we selected dichotic digit test (DDT) [18]/ pitch pattern sequence test (PPS) [19]/monaural selective auditory attention test (mSAAT) [20] based on MAPA (multiple auditory processing assessment) test battery $[21,22]$. MAPA study showed that DDT/PPS/mSAAT test battery can provide $90 \%$ sensitivity and $100 \%$ specificity in (C)APD diagnosis $[8,21]$. Before starting study, to establish norms for Persian-version of DDT (free recall) [18],
mSAAT-Persian version [20], PPS test [19] and spatial word recognition score in noise test, we conduct a study on 750 students of 8 to 12 years old (mean age $10.00 \pm 1.41 ; 250$ males and 500 females). For establishing normative data, inclusion criteria were as follows: normal PTA (auditory threshold less than $20 \mathrm{~dB}$ HL in 500 to $4,000 \mathrm{~Hz}$ frequency range) in both ears; normal middle ear function (A type tympanogram); 85 or higher Wechsler intelligence quotient (IQ) score, monolingualism (Persian language); no history of attention-deficit hyperactivity disorder (ADHD), seizures, behavioral or developmental disorders; not being on any central nervous system medications; good academic performance. Normative data can be found in result section.

Inclusion criteria for children suspected to (C)APD were as follows: normal PTA (auditory threshold less than $20 \mathrm{~dB} \mathrm{HL}$ in 500 to $4,000 \mathrm{~Hz}$ frequency range) in both ears; symmetric hearing (PTA difference less than $5 \mathrm{dBHL}$ between two ears); normal middle ear function (A type tympanogram); 85 or higher Wechsler IQ score, monolingualism (Persian language); no history of ADHD, seizures, behavioral or developmental disorders; not being on any central nervous system medications; poor academic performance; abnormal results in DDT, PPS and mSAAT. If a child had scores less than 2 standard deviations from established norms in these three tests, he/she was suspected to (C)APD.

\section{Procedure}

DDT is composed of naturally spoken digits from 1 to 10 (except for number 4 in Persian language). It requires that 2 number pairs be presented simultaneously to each ear of listeners, and subjects are asked to repeat all 4 numbers regardless of order (free recall). Forty patterns are presented in total. Outcome measure is the percentage of correct responses [18].

PPS test reflects temporal component of auditory pattern recognition. Each item is a set of three pure tones with two different pitches, with a low-frequency tone at $880 \mathrm{~Hz}$ and a high-frequency tone at $1,122 \mathrm{~Hz}$. The duration of every tone is $200 \mathrm{~ms}$ with $10-\mathrm{ms}$ rise and fall time. These tones are separated by $150-\mathrm{ms}$ intervals and the silence epoch between every set is $6 \mathrm{~s}$. Totally 30 patterns are presented monaurally to each ear. Stimuli were presented at $55 \mathrm{~dB}$ SL (re: $1,000 \mathrm{~Hz}$ threshold). Outcome of this test is percentage of correct responses [19].

To evaluate speech understanding in presence of competing signals, the Persian version of mSAAT was used. This test is one of the monaural low redundancy tests and it can assess auditory figure-ground skill [23]. This test compares ability of recognizing monosyllabic words ( 25 words) embedded in 
a background of story. Both target and competing stimuli are recorded by the same speaker and signal to noise ratio (SNR) is zero $\mathrm{dB}$. Outcome measure is percentage of correct responses for each ear [20].

To evaluate spatial processing, auditory lateralization of monosyllabic words in white noise with zero dB SNR was used. Words were presented randomly through headphones at $-90,-60,-30$, zero, $+30,+60,+90^{\circ}$ azimuth (5 words were presented for each location). Test was made by Sound Forge software v8. Word recognition score (WRS) and number of auditory lateralization errors were examined for each spatial location.

Auditory lateralization training including 12 formal sessions ( 2 sessions in each week) was started in the training group. Each session lasted 45 minutes. A high pass and a low pass noise with $2 \mathrm{kHz}$ cutoff point, with 250 milliseconds duration and 20 milliseconds rise and fall times were used. Stimuli were presented through headphones with 880,660 , 220, zero, $-220,-660,-880$ microseconds ITDs at $50 \mathrm{~dB} \mathrm{HL}$, and the children had to point to the perceived location of sound source [24]. In localization training, loudspeakers are used to make an auditory space around subjects and in lateralization training, sound is delivered through headphones. Headphones are preferable because under headphones, ITD and ILD can be manipulated independently $[25,26]$. These sessions were performed as a game. If the child could point to the correct sound position, he/she received a reward. There were 7 pictures of loudspeakers, in $-90,-60,-30,0,+30,+60$, $+90^{\circ}$ around children. At the beginning of each training session, the administrator participated actively in the lateralization game then gradually the child took over the games and the administrator just gave feedback and rewards based on the child's response.

In the training group, mSAAT and lateralization test were performed again after 12 sessions of lateralization training. For comparison and determining training effects, in the control group, mSAAT and lateralization test were also repeated after 2 months from the first evaluation.

SPSS v21 (IBM, Armonk, NY, USA) was used for statistical data analysis. In addition to descriptive analysis, covariance and Wilcoxon tests were used to show training effects and within group comparisons respectively.

Written consent was received from the parents for evaluation and auditory lateralization sessions. All tests were noninvasive. The control group also received auditory lateralization training after research. Patients' information were kept private.

\section{Results}

750 normal children ( 8 to 12 years old; mean age $10.00 \pm$ 1.41 year) including 250 males and 500 females were selected and used for establishing normative data. The means and standard deviations (SDs) of mSAAT-Persian version, Persian version of DDT and PPS test are shown in Table 1. Results of children suspected to (C)APD is also shown in Table 1. As it can be seen children suspected to (C)APD had lower scores in all tests (more than 2 SDs). Means and SDs of number of lateralization errors and spatial WRS in noise for normal children and children suspected to (C)APD are summarized in Table 2. In all spatial directions, children suspected to (C)APD have higher lateralization errors and lower spatial WRS score (more than 2 SDs) than normal children.

Table 3 shows results of speech understanding in noise

Table 1. mSAAT, DDT and PPS test scores: normative and (C)APD data (mean \pm SDs)

\begin{tabular}{lcccccc}
\hline & Number & \multicolumn{2}{c}{ mSAAT } & & \multirow{2}{*}{ DDT } & PPS \\
\cline { 3 - 4 } & of cases & Right ear & Left ear & & \\
\hline Normative data & 750 & $91.86( \pm 5.47)$ & $90.19( \pm 5.89)$ & & $82.21( \pm 7.20)$ & $91.47( \pm 4.05)$ \\
(C)APD data & 60 & $64.16( \pm 2.15)$ & $64.10( \pm 2.12)$ & & $63.33( \pm 7.92)$ & $64.00( \pm 3.29)$ \\
\hline
\end{tabular}

SD: standard deviation, mSAAT: monaural selective auditory attention test, DDT: dichotic digit test, PPS: pitch pattern sequence test, (C)APD: central auditory processing disorder

Table 2. Lateralization errors and spatial WRS in noise (percent) scores: normative and (C)APD data (mean \pm SDs)

\begin{tabular}{|c|c|c|c|c|c|c|c|c|}
\hline & $\begin{array}{l}\text { Number } \\
\text { of cases }\end{array}$ & At $-90^{\circ}$ & At $-60^{\circ}$ & At $-30^{\circ}$ & At $0^{\circ}$ & At $+30^{\circ}$ & $\mathrm{A} t+60^{\circ}$ & $\mathrm{A} t+90^{\circ}$ \\
\hline \multicolumn{9}{|l|}{ Number of errors } \\
\hline Normative data & 750 & $0.10( \pm 0.31)$ & $0.08( \pm 0.28)$ & $0.03( \pm 0.16)$ & $0.02( \pm 0.13)$ & $0.03( \pm 0.16)$ & $0.09( \pm 0.31)$ & $0.10( \pm 0.33)$ \\
\hline (C)APD data & 60 & $2.95( \pm 0.62)$ & $2.88( \pm 0.61)$ & $1.35( \pm 0.48)$ & $1.46( \pm 0.50)$ & $1.30( \pm 0.46)$ & $2.88( \pm 0.61)$ & $2.95( \pm 0.62)$ \\
\hline \multicolumn{9}{|l|}{ WRS in noise } \\
\hline Normative data & 750 & $99.41( \pm 3.37)$ & $99.40( \pm 3.25)$ & $99.65( \pm 2.61)$ & $100( \pm 0.00)$ & $99.47( \pm 3.22)$ & $99.36( \pm 3.52)$ & $99.25( \pm 3.79)$ \\
\hline (C)APD data & 60 & $33.00( \pm 9.61)$ & $37.33( \pm 6.85)$ & $56.00( \pm 9.60)$ & $53.33( \pm 10.84)$ & $56.00( \pm 8.86)$ & $36.66( \pm 8.36)$ & $35.00( \pm 8.73)$ \\
\hline
\end{tabular}

SD: standard deviation, WRS: word recognition score, (C)APD: central auditory processing disorder 
Table 3. Speech understanding in the training and control groups in time (mean \pm SDs)

\begin{tabular}{|c|c|c|c|c|c|c|c|c|c|}
\hline & $\begin{array}{l}\text { mSAAT right } \\
\text { ear }\end{array}$ & $\begin{array}{l}\text { mSAAT left } \\
\text { ear }\end{array}$ & $\begin{array}{l}\text { WRS in noise } \\
\text { at }-90^{\circ}\end{array}$ & $\begin{array}{l}\text { WRS in noise } \\
\text { at }-60^{\circ}\end{array}$ & $\begin{array}{l}\text { WRS in noise } \\
\text { at }-30^{\circ}\end{array}$ & $\begin{array}{c}\text { WRS in noise } \\
\text { at zero }\end{array}$ & $\begin{array}{c}\text { WRS in noise } \\
\text { at }+30^{\circ}\end{array}$ & $\begin{array}{c}\text { WRS in noise } \\
\text { at }+60^{\circ}\end{array}$ & $\begin{array}{c}\text { WRS in noise } \\
\text { at }+90^{\circ}\end{array}$ \\
\hline \multicolumn{10}{|l|}{ Control } \\
\hline Before & $\begin{array}{c}64.20 \\
( \pm 2.31)\end{array}$ & $\begin{array}{c}64.33 \\
( \pm 2.23)\end{array}$ & $\begin{array}{c}34.00 \\
( \pm 9.32)\end{array}$ & $\begin{array}{c}37.33 \\
( \pm 6.91)\end{array}$ & $\begin{array}{c}56.00 \\
( \pm 9.68)\end{array}$ & $\begin{array}{c}54.00 \\
( \pm 10.69)\end{array}$ & $\begin{array}{c}58.00 \\
( \pm 8.05)\end{array}$ & $\begin{array}{c}35.33 \\
( \pm 10.08)\end{array}$ & $\begin{array}{l}36.66 \\
( \pm 7.58)\end{array}$ \\
\hline After & $\begin{array}{c}64.66 \\
( \pm 2.18)\end{array}$ & $\begin{array}{c}63.26 \\
( \pm 1.99)\end{array}$ & $\begin{array}{c}33.33 \\
( \pm 9.58)\end{array}$ & $\begin{array}{c}35.33 \\
( \pm 8.60)\end{array}$ & $\begin{array}{c}53.33 \\
( \pm 9.58)\end{array}$ & $\begin{array}{c}55.33 \\
( \pm 8.60)\end{array}$ & $\begin{array}{c}34.66 \\
( \pm 8.99)\end{array}$ & $\begin{array}{c}51.33 \\
( \pm 11.36)\end{array}$ & $\begin{array}{c}34.66 \\
( \pm 8.99)\end{array}$ \\
\hline \multicolumn{10}{|l|}{ Training } \\
\hline Before & $\begin{array}{c}64.13 \\
( \pm 2.02)\end{array}$ & $\begin{array}{c}63.86 \\
( \pm 2.02)\end{array}$ & $\begin{array}{c}32.00 \\
( \pm 9.96)\end{array}$ & $\begin{array}{c}37.33 \\
( \pm 6.91)\end{array}$ & $\begin{array}{c}56.00 \\
( \pm 9.68)\end{array}$ & $\begin{array}{c}52.66 \\
( \pm 11.12)\end{array}$ & $\begin{array}{c}54.00 \\
( \pm 9.32)\end{array}$ & $\begin{array}{c}38.00 \\
( \pm 6.10)\end{array}$ & $\begin{array}{c}33.33 \\
( \pm 9.58)\end{array}$ \\
\hline After & $\begin{array}{c}81.20 \\
( \pm 3.66)\end{array}$ & $\begin{array}{c}81.20 \\
( \pm 4.15)\end{array}$ & $\begin{array}{c}45.33 \\
( \pm 10.41)\end{array}$ & $\begin{array}{c}44.00 \\
( \pm 9.68)\end{array}$ & $\begin{array}{c}64.00 \\
( \pm 8.13)\end{array}$ & $\begin{array}{c}67.33 \\
( \pm 9.80)\end{array}$ & $\begin{array}{c}66.00 \\
( \pm 9.32)\end{array}$ & $\begin{array}{c}52.00 \\
( \pm 9.96)\end{array}$ & $\begin{array}{c}46.66 \\
( \pm 9.58)\end{array}$ \\
\hline
\end{tabular}

SD: standard deviation, WRS: word recognition score, mSAAT: monaural selective auditory attention test

Table 4. Auditory lateralization errors in the training and control groups in time (mean \pm SDs)

\begin{tabular}{cccccccc}
\hline & $\begin{array}{c}\text { Error number } \\
\text { at }-90^{\circ}\end{array}$ & $\begin{array}{c}\text { Error number } \\
\text { at }-60^{\circ}\end{array}$ & $\begin{array}{c}\text { Error number } \\
-30^{\circ}\end{array}$ & $\begin{array}{c}\text { Error number } \\
\text { at zero }\end{array}$ & $\begin{array}{c}\text { Error number } \\
\text { at }+30^{\circ}\end{array}$ & $\begin{array}{c}\text { Error number } \\
+60^{\circ}\end{array}$ & $\begin{array}{c}\text { Error number } \\
\text { at }+90^{\circ}\end{array}$ \\
\hline $\begin{array}{c}\text { Control } \\
\text { Before }\end{array}$ & $3.03( \pm 0.55)$ & $2.96( \pm 0.61)$ & $1.36( \pm 0.49)$ & $1.40( \pm 0.49)$ & $1.30( \pm 0.46)$ & $3.00( \pm 0.58)$ & $3.00( \pm 0.52)$ \\
$\begin{array}{l}\text { After } \\
\text { Training }\end{array}$ & $3.16( \pm 0.59)$ & $3.03( \pm 0.66)$ & $1.53( \pm 0.68)$ & $1.63( \pm 0.71)$ & $1.53( \pm 0.73)$ & $3.06( \pm 0.66)$ & $3.06( \pm 0.56)$ \\
Before & $2.86( \pm 0.68)$ & $2.80( \pm 0.66)$ & $1.33( \pm 0.47)$ & $1.53( \pm 0.50)$ & $1.30( \pm 0.46)$ & $2.76( \pm 0.62)$ & $2.90( \pm 0.71)$ \\
After & $2.46( \pm 0.50)$ & $1.76( \pm 0.50)$ & $0.53( \pm 0.50)$ & $0.46( \pm 0.50)$ & $0.63( \pm 0.49)$ & $1.76( \pm 0.50)$ & $2.40( \pm 0.49)$ \\
\hline SD: standard deviation & & & & & &
\end{tabular}

(spatial WRS in noise test) and in presence of competing signals (mSAAT) and Table 4 shows results of auditory lateralization errors (number of errors) in the training and control groups before and after the auditory lateralization training (percent).

Covariance test showed that in the training group, the mSAAT score in right and left ear, spatial WRS in noise at $-90,-60,-30$, zero, $+30,+60,+90^{\circ}$ improved significantly $(p$ value $\leq 0.001)$ and number of lateralization errors at $-90,-60$, -30 , zero, $+30,+60$, and $90^{\circ}$ azimuth decreased significantly ( $p$ value $\leq 0.001$ ) after auditory lateralization training.

Kolmogorov-Smirnov test showed that mSAAT, spatial WRS in noise and number of auditory lateralization errors at $-90,-60,-30$, zero, $+30,+60,+90^{\circ}$ azimuth had non-normal distribution in both training and control groups ( $p$ value $\leq 0.001$ ). Wilcoxon test was used for comparing results within each group. In control group mSAAT score in right ear did not show any significant changes after 2 months ( $p$ value $=$ $0.05)$ but left ear showed significant decline ( $p$ value $=0.03)$. In the training group mSAAT score in both ears showed significant improvement after the auditory lateralization training ( $p$ value $\leq 0.001$ ) (Table 5 ). The spatial WRS results showed that in the control group, WRS declined significantly at $-30,+30$ and $+60^{\circ}$ azimuth after 2 months. WRS at the remaining positions were unchanged. In the training group, spatial WRS in noise improved significantly at all the posi-
Table 5. mSAAT score (percent) in the training and control group in time (mean \pm SDs)

\begin{tabular}{lcc}
\hline & mSAAT right ear & mSAAT left ear \\
\hline $\begin{array}{l}\text { Control } \\
\text { Before }\end{array}$ & $64.20( \pm 2.31)$ & $64.33( \pm 2.23)$ \\
After & $64.66( \pm 2.18)$ & $63.26( \pm 1.99)$ \\
Training & & \\
Before & $64.13( \pm 2.02)$ & $63.86( \pm 2.01)$ \\
After & $81.20( \pm 3.66)$ & $81.21( \pm 4.15)$ \\
\hline SD: standard deviation, mSAAT: monaural selective auditory
\end{tabular}
attention test

tions ( $p$ value $\leq 0.001$ ). The number of auditory lateralization errors in the control group did not show any significant change after 2 months ( $p$ value was 0.31 at $-30^{\circ}$ azimuth and 1.00 for other spatial locations). In the training group, there was a significant error reduction at all the locations ( $p$ value $\leq 0.001$ ).

\section{Discussion}

Children suspected to (C)APD were selected and based on our hypothesis about importance of spatial abilities in understanding speech in noise/competing signal, they were trained by using an auditory lateralization practice and finally changes in spatial WRS in noise and mSAAT score were tracked. There are few studies about spatial hearing and its relation to speech understanding in noise in children with (C)APD. 
Studies with similar concepts will be used for discussion.

In this study spatial WRS in noise and mSAAT score in children with (C)APD was more than 2 SDs below normal children and number of lateralization errors were more than 2 SDs higher than normal children before training. These tests can recognize the most common complaint of children with (C)APD which is understanding speech in background noise and in presence of competing signals [8,27-30]. These results are in agreement with other studies [23,27,28,30-37]. This is an important issue because learning at elementary schools are primarily auditory-verbal and classrooms are inherently noisy places [38-43]. The ability to recognize location of target speech and focusing attention to it when there are other competing signals is critical for understanding speech in everyday situations. Cameron and Dillon created a special and three dimensional speech in noise test under headphone. This test is called listening in spatialized noisesentence test. They mentioned that a large proportion of children suspected to (C)APD suffer from spatial hearing disorder and it means they are not able to focus on speech that is coming from one direction and suppress simultaneous signals that are coming from other directions. This is why they have more difficulty listening in everyday noisy environments $[13,14,28]$. Jerger [44] mentioned that main underlying cause for (C)APD (listening problems in noisy environments) can be auditory space representation problems and that spatial hearing problems can give rise to sound source streaming problems [13]. Our study likewise showed that children suspected to (C)APD have more lateralization errors and they have speech understanding difficulties in noise in different spatial directions and when there is a competing signal.

After lateralization training, number of auditory lateralization errors fell down significantly in only training group. Many human and animal studies have shown that appropriate localization/lateralization training can reduce spatial errors in time. Localization/lateralization training has been used in many animal researches, blind humans, and even normalhearing adults in virtual auditory field researches and in almost all of these researches, spatial training has been found effective [14,24,45-48]. In animals (e.g., owls or ferrets) occluding one ear canal immediately leads to severe increase in localization errors due to changes in binaural cues. After localization experience in this new condition, errors showed significant reduction. This is indicative of high plasticity of auditory localization [46,49-51]. In blind humans, localization training in format of playing games (e.g., Hoy-Pippi or virtual auditory games) can improve auditory localization skills dramatically in only a few days [52,53]. Spatial hearing plasticity is significant during development and still remains plastic in adulthood. Putting a plug inside one ear canal changes spatial cues, but human adults can relearn localization in time $[47,54]$. It seems that relearning is due to reweighting in localization circuits and new spatial maps [54].

After auditory lateralization training mSAAT and spatial WRS score showed significant improvement in only training group. The control group did not show any significant changes. Since we only used auditory lateralization training, these improvements can be attributed to lateralization training. Cameron and Dillon developed and used LiSN \& Learn software (NAL, New South Wales, Australia) for remediating spatial processing disorder in children suspected to (C) APD. This software can be used at home and it is a training game. A pair of headphones is used for delivering stimuli. Child has to perceive a target word nested within a sentence that is delivered from zero degree and ignore other competing sentences that are sent from $\pm 90^{\circ}$ azimuth. After 120 game sessions, children with SPDs showed $10.9 \mathrm{~dB}$ improvements for speech reception thresholds and responses from parents, teachers, and self-reported questionnaires showed positive outcomes [14,55,56].

Finally it should be noted that we used auditory lateralization training for a time period of 6 weeks and showed that auditory lateralization can improve speech understanding in noise significantly. The generalization of this results needs further researches. The authors recommend other studies with higher sample size and auditory lateralization training for more extended time period. Furthermore we recommend follow up evaluations several months after completion of auditory training to see if these results are long term.

\section{Acknowledgments}

We thank our colleague Dr. Saeedeh Mehrkian who provided insight and expertise that greatly assisted the research.

\section{Conflicts of interest}

The authors have no financial conflicts of interest.

\section{REFERENCES}

1) Schnupp J, Nelken I, King A. Auditory Neuroscience: Making Sense of Sound. Cambridge, MA: MIT Press;2011.

2) Sonnadara RR, Alain C, Trainor LJ. Occasional changes in sound location enhance middle latency evoked responses. Brain Res 2006; 1076:187-92.

3) Devore S, Ihlefeld A, Hancock K, Shinn-Cunningham B, Delgutte B. Accurate sound localization in reverberant environments is mediated by robust encoding of spatial cues in the auditory midbrain. Neuron 2009;62:123-34.

4) Plack CJ. Oxford Handbook of Auditory Science: Hearing. Oxford: Oxford University Press;2010.

5) Pickora-Fuller MK. Processing speed and timing in aging adults: psychoacoustics, speech perception, and comprehension. Int J Audiol 2003;42 Suppl 1:S59-67.

6) Bodden M. Auditory demonstrations of a cocktail-party-processor. 
Acta Acust United Acust 1996;82:356-7.

7) Itoh K, Yumoto M, Uno A, Kurauchi T, Kaga K. Temporal stream of cortical representation for auditory spatial localization in human hemispheres. Neurosci Lett 2000;292:215-9.

8) Musiek FE, Chermak GD. Handbook of (Central) Auditory Processing Disorder Volume 1: Auditory Neuroscience and Diagnosis. San Diego, CA: Plural Publishing Inc.;2013.

9) Cherry R, Rubinstein A. Comparing monotic and diotic selective auditory attention abilities in children. Lang Speech Hear Serv Sch 2006;37:137-42.

10) Delb W, Strauss DJ, Hohenberg G, Plinkert PK. The binaural interaction component (BIC) in children with central auditory processing disorders (CAPD). Int J Audiol 2003;42:401-12.

11) Gomez R, Condon M. Central auditory processing ability in children with ADHD with and without learning disabilities. J Learn Disabil 1999;32:150-8.

12) Schow RL, Chermak G. Implications from factor analysis for central auditory processing disorders. Am J Audiol 1999;8:137-42.

13) Cameron S, Dillon H. Development of the Listening in Spatialized Noise-Sentences Test (LISN-S). Ear Hear 2007;28:196-211.

14) Cameron S, Glyde H, Dillon H. Efficacy of the LiSN \& Learn auditory training software: randomized blinded controlled study. Audiol Res 2012;2:e15.

15) Banai K, Kraus N. Neurobiology of (central) auditory processing disorder and language-based learning disability. In: Musiek F, Chermak G, editors. Handbook of (central) auditory processing disorder: Auditory Neuroscience and Diagnosis. San Diego: Plural Publishing;2007. p.89-116.

16) Geffner DS, Ross-Swain D. Auditory processing disorders: Assessment, management, and treatment. San Diego: Plural Pub.;2007.

17) Lotfi Y, Mehrkian S, Moossavi A, Zadeh SF, Sadjedi H. Relation between working memory capacity and auditory stream segregation in children with auditory processing disorder. Iran J Med Sci 2016; 41:110-7.

18) Nejati V, Alipour F, Karimi LJ, Esfandiari L. Persian version of the dichotic digit test for children: design and evaluation of the psychometric properties. Audit Ves Res 2016;25:55-62.

19) Sanayi R, Mohamadkhani G, Pourbakht A, Jalilvand L, Jalayi S, Shokri S. Auditory temporal processing abilities in early azari-persian bilinguals. Iran J Otorhinolaryngol 2013;25:227-32.

20) Aarabi S, Jarollahi F, Jalaie S. Development and determination of the validity of Persian version of monaural selective auditory attention test in learning disabled children. Audit Ves Res 2016;25:49-54.

21) Domitz DM, Schow RL. A new CAPD battery--multiple auditory processing assessment: factor analysis and comparisons with SCAN. Am J Audiol 2000;9:101-11.

22) Ebadi E, Jarollahi F, Tahaei AA, Ahadi M, Hosseini AF. Development and evaluation of the Persian version of the multiple auditory processing assessment Audit Vesti Res 2016;25:75-81.

23) Welling DR, Ukstins CA. Fundamentals of Audiology For The Speech-Language Pathologist. Burlington, MA: Jones \& Bartlett Publishers;2013.

24) Moosavi A, Hosseini dastgerdi Z, Lotfi Y, Mehrkian S, Bakhshi E, Khavar Ghazalani B. Auditory Lateralization Ability in children with (Central) Auditory Processing Disorder. IRJ 2014;12:31-7.

25) Grantham DW. Spatial hearing and related phenomena. In: Moore BCJ, editor. Hearing. London: Academic;1995. p.297-345.

26) Wright BA, Zhang Y. A review of learning with normal and altered sound-localization cues in human adults Int J Audiol 2006;45 Suppl 1:S92-8.

27) Bellis TJ. Assessment and Management of Central Auditory Processing Disorders in the Educational Setting From Science to Practice. San Diego, CA: Plural Publishing;2011.

28) Cameron S, Dillon H. The listening in spatialized noise-sentences test (LISN-S): comparison to the prototype LISN and results from children with either a suspected (central) auditory processing disor- der or a confirmed language disorder. J Am Acad Audiol 2008;19: $377-91$.

29) Chermak GD, Zielonko B. Word discrimination in the presence of competing speech with children. J Am Audiol Soc 1977;2:188-92.

30) Cherry R. Screening and evaluation of central auditory processing disorders in young children. In: Katz J, Stecker N, Henderson D, editors. Central Auditory Processing: A Transdisciplinary View. St. Louis: Mosby Yearbook Inc.; 1992. p.129-40.

31) American Speech-Language Hearing Association. Central auditory processing: Current status of research and implications for clinical practice. Am J Audiol 1996;5:41-52.

32) Muchnik C, Ari-Even Roth D, Othman-Jebara R, Putter-Katz H, Shabtai EL, Hildesheimer M. Reduced medial olivocochlear bundle system function in children with auditory processing disorders. Audiol Neurootol 2004;9:107-14.

33) Heine C, Slone M. The impact of mild central auditory processing disorder on school performance during adolescence. J Sch Health 2008;78:405-7.

34) Weihing J. FM systems as a treatment for CAPD. Hear J 2005;58:74.

35) Musiek F. Habilitation and management of auditory processing disorders: overview of selected procedures. J Am Acad Audiol 1999; 10:329-42.

36) Pelchar T. (Central) Auditory Processing Disorder. In: Goldstein S, Naglieri JA, editors. Encyclopedia of Child Behavior and Development. New York: Springer;2011. p.173-5.

37) Ferguson MA, Hall RL, Riley A, Moore DR. Communication, listening, cognitive and speech perception skills in children with auditory processing disorder (APD) or Specific Language Impairment (SLI). J Speech Lang Hear Res 2011;54:211-27.

38) Arnold P, Canning D. Does classroom amplification aid comprehension? Br J Audiol 1999;33:171-8.

39) Cobb C. Turning on a dime: Making change in literacy classrooms. Read Teach 2004;28:104-6.

40) Eales RT, Neale DC, Carroll JM. Desktop video conferencing as a basis for computer supported collaborative learning in K-12 classrooms. In: Collis B, Oliver R, editors. Proceedings of EdMedia 99 World Conference on Educational Multimedia, Hypermedia \& Telecommunications (Seattle, 19-24 June). Charlottesville, VA: Association for the Advancement of Computing in Education;1999. p.628-33.

41) Nelson PB, Soli S. Acoustical barriers to learning children at risk in every classroom. Lang Speech Hear Serv Sch 2000;31:356-61.

42) Picard M, Bradley JS. Revisiting Speech Interference in Classrooms: Revisando la interferencia en el habla dentro del salón de clases. Int J Audiol 2001;40:221-44.

43) Rosen S, Cohen M, Vanniasegaram I. Auditory and cognitive abilities of children suspected of auditory processing disorder (APD). Int J Pediatr Otorhinolaryngol 2010;74:594-600.

44) Jerger J. Controversial issues in central auditory processing disorders. Semin Hear 1998;19:395-400.

45) Casseday JH, Neff WD. Auditory localization: role of auditory pathways in brain stem of the cat. J Neurophysiol 1975;38:842-58

46) Kacelnik O, Nodal FR, Parsons $\mathrm{CH}$, King AJ. Training-induced plasticity of auditory localization in adult mammals. PLoS Biol 2006; 4:e71.

47) Kumpik DP, Kacelnik O, King AJ. Adaptive reweighting of auditory localization cues in response to chronic unilateral earplugging in humans. J Neurosci 2010;30:4883-94.

48) Lewald J. Opposing effects of head position on sound localization in blind and sighted human subjects. Eur J Neurosci 2002;15:1219-24.

49) Knudsen EI, Esterly SD, Knudsen PF. Monaural occlusion alters sound localization during a sensitive period in the barn owl. J Neurosci 1984;4:1001-11.

50) Knudsen EI, Knudsen PF, Esterly SD. A critical period for the recovery of sound localization accuracy following monaural occlusion in the barn owl. J Neurosci 1984;4:1012-20. 
51) Moore DR, Hine JE, Jiang ZD, Matsuda H, Parsons CH, King AJ. Conductive hearing loss produces a reversible binaural hearing impairment. J Neurosci 1999;19:8704-11.

52) Ohuchi M, Iwaya $Y$, Suzuki $Y$, Munekata T. A game for visually impaired children with a 3-d virtual auditory display. Proceedings of the 9th International Conference on Auditory Display. Boston: Boston University;2003.

53) Ohuchi M, Iwaya Y, Suzuki Y, Munekata T. Training effect of a virtual auditory game on sound localization ability of the visually impaired. Presented at the 11th International Conference on Auditory Display (ICAD2005). Limerick, Ireland: Georgia Institute of Technology International Community on Auditory Display;2005.
54) Irving S, Moore DR. Training sound localization in normal hearing listeners with and without a unilateral ear plug. Hear Res 2011;280: $100-8$.

55) Cameron S, Dillon H. Remediation of spatial processing issues in central auditory processing disorder. In: Chermak GD, Musiek FE, editors. Handbook of Central Auditory Processing Disorder. Comprehensive Intervention. San Diego, CA: Plural Publishing;2014. p.201-24.

56) Lo CY, Dillon H, Cameron S, Mcmahon CM. Evaluation of headphone effects on performance in the LiSN \& Learn auditory training software. ANU Undergrad Res J 2015:147-59. 